\title{
Performance Analysis of the Overcurrent Protection for the Distributed Renewable Generation Dominated Microgids
}

\author{
*Md Asif Uddin Khan, Qiteng Hong, Adam Dyśko and Campbell Booth \\ Department of Electronic and Electrical Engineering \\ University of Strathclyde \\ Glasgow, United Kingdom \\ *Email: asif.u.khan@strath.ac.uk
}

\begin{abstract}
This paper aims to present a study of the conventional protection scheme i.e. overcurrent (OC) protection's malfunctioning in the microgrids dominated by inverter interfaced distributed generator (IIDG) under a range of scenarios by injecting faults at different locations of the network. Due low cost and inherent back-up protection, overcurrent protection scheme is generally used in the distribution network and microgrids. However, integration of IIDG in large number might introduce several protection challenges for microgrids. Different literature discusses the protection issues that might arise in microgrids due to addition of distributed generation, but those challenges are not practically studied. Hence, in this paper several fault cases by changing fault positions and using different combinations of IIDG in the network are simulated to fully explore the protection challenges and to analyze as well as to demonstrate the effectiveness of the overcurrent relays in the IIDG dominated microgrids.
\end{abstract}

Keywords-microgrids, fault, overcurrent relay, inverter interfaced distributed generation (IIDG).

\section{INTRODUCTION}

Power system protection ensures reliable power supply and safety of the power system's equipment, personal and public. Overcurrent relays that measures current magnitude are responsible to detect faults in the distribution line. The overcurrent scheme is designed for strong power system, dominated by large synchronous generation and based on the assumption that during fault large fault current will flow. However, targeting reduction (or even elimination) of carbon emission and addressing environmental concern, large number of renewable generation (wind, solar, etc.) are integrating with the distribution level, close the loads [1]. These sources require inverter to interface with ac network and hence are known as inverter interfaced distributed generator (IIDG).

Microgrids are the new architecture of power generation and delivery system that can effectively manage the integration of IIDG (or small-scale DG) and loads as a small controllable subsystem of distribution network which can operate as an individual (islanded mode) system or in parallel with the grid (grid connected mode) [2]. While the traditional distribution network is radial in nature (unidirectional power flow from generation to load), microgrids are active (bidirectional power flow) i.e. net export/import during grid connected mode and power balancing/sharing during islanded mode is possible. The ability of the microgrids to operate in both modes, islanded mode and grid connected mode, ensures resilience of power system and availability of the power supply [3]. Nevertheless, microgrid suffers from different technical challenges and protection is one of the major problems for its successful operation [4].
The fault current level is expected to be high during grid connected mode of operation assuming system is strong with several conventional synchronous generation, but during islanded operation, fault current is significantly low. Moreover, due to thermal overcurrent capacity of power electronics-based inverters, the fault current contribution from IIDGs are limited to 1.5 times of the rated value [5]. Furthermore, the fault behaviour of these IIDGs are very different from conventional generation [6]. Hence, it has been assumed that conventional overcurrent scheme with inverse definite minimum time (IDMT) characteristics may not suitable enough for the protection of microgrid or future distribution network [7]. However, this assumption is not practically demonstrated in the literature. Thus, this paper will analyse the performance of the overcurrent protection scheme with different realistic situations that may arise in the system due to large integration of IIDGs.

The rest of the paper is organized in the following way: section Error! Reference source not found. will present the developed microgrid model and design of the overcurrent relay that is used for the study, section Error! Reference source not found. will discuss about some future scenarios and simulation results to analyse the protection feature of the overcurrent relay, and finally section Error! Reference source not found. will conclude the paper by suggesting appropriate protection scheme to solve the issues.

\section{Simulation MODEL OF MiCROGRID AND OVERCURRENT RELAY}

To understand the protection challenges and to observe the performance of the overcurrent scheme on microgrid, a simple and realistic model of microgrid is designed in the Simulink, MATLAB and is shown in the Fig. 1. From the figure it can be seen that there are three buses and each bus can contain IIDG and load. The connection each IIDG in the buses is flexible and can be disconnected from the network based on the simulation cases which will discussed in detail later in section Error! Reference source not found.. The microgrid can get connected and disconnected with distribution grid of $11 \mathrm{kV}$. A controllable switch at the point of interconnection can enable the grid connected and islanded mode when necessary.

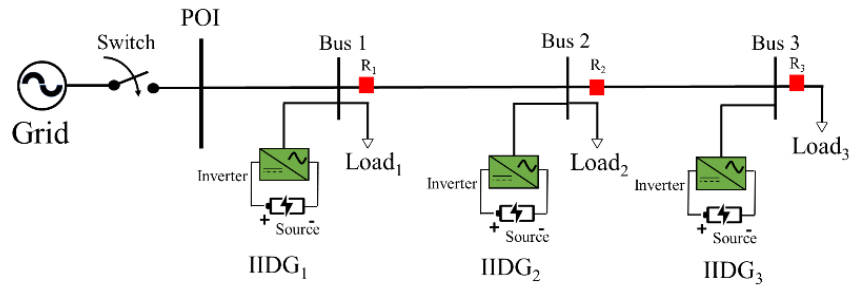

Fig. 1. Designed microgrid to test the overcurrent relay. 
Different control strategies can be used to control the IIDGs in the microgrid [8]. However, in this study during grid connected mode, only PQ (real and reactive power) control strategy is used (e.g. all the IIDGs in Fig. 1 is controlled by PQ controller) but during islanded mode, only IIDG1 (shown in Fig. 1) works as grid forming generator i.e. only IIDG1 uses $\mathrm{V} / \mathrm{F}$ (voltage and frequency) controller and rest of the IIDGs are PQ controlled. The detailed models of these controllers are discussed in [9]. Fig. 2 shows the connection of the IIDG to the microgrid. As can be seen from the figure, a fixed dc voltage source is used before the power electronics based IGBT (Insulated Gate Bipolar Transistor) inverter for the simplification of the study and a LC filter is used to remove higher order harmonics. Line parameters are set, based on [10] and other details of the line and IIDGs are presented in TABLE I.

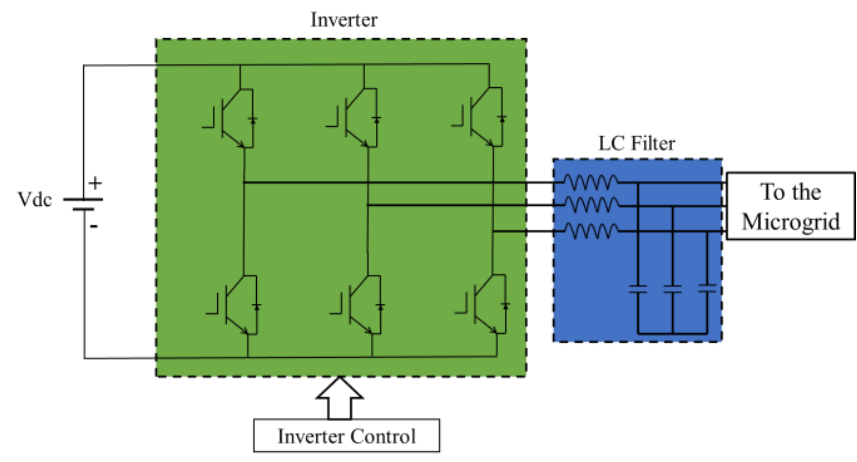

Fig. 2. Connection of each IIDG unit to microgrid.

TABLE I. LINE AND SySTEM PARAMETERS For THE SimULATIONS

\begin{tabular}{|c|c|}
\hline $\begin{array}{l}\text { Simulation } \\
\text { Parameters }\end{array}$ & Description and value \\
\hline Line impedance & $Z_{\text {Line }}=(0.543+j 0.395) \Omega / \mathrm{km}$ \\
\hline Line length & $\begin{array}{l}\text { Line between POI and Bus } 1, l_{01}=0.5 \mathrm{~km} \text {, } \\
\text { Line between Bus } 1 \text { and Bus } 2, l_{12}=1.8 \mathrm{~km} \text {, } \\
\text { Line between Bus } 2 \text { and Bus } 3, l_{23}=2 \mathrm{~km} \text { and } \\
\text { Line after Bus } 3, l_{3}=1 \mathrm{~km}\end{array}$ \\
\hline IIDG rating & $500 \mathrm{kVA}$ (for each generator) \\
\hline $\begin{array}{l}\text { Reference value of } \\
\text { IIDGs }\end{array}$ & $\begin{array}{l}I I D G_{1}=300 \mathrm{kVA} \\
I I D G_{2}=100 \mathrm{kVA} \text { and } \\
I I D G_{3}=50 \mathrm{kVA}\end{array}$ \\
\hline LC Filter & $L=2 m H$ and $C=72 \mu F$ \\
\hline Load rating & $\begin{array}{l}\operatorname{Load}_{1}=300 \mathrm{~kW} \\
\operatorname{Load}_{2}=200 \mathrm{~kW} \\
\operatorname{Load}_{3}=100 \mathrm{~kW} \text { and } \\
\text { rest of the network }=50 \mathrm{~kW} \\
\text { Total Load }=650 \mathrm{~kW}\end{array}$ \\
\hline
\end{tabular}

The overcurrent relays, $\mathrm{R}_{1}, \mathrm{R}_{2}$ and $\mathrm{R}_{3}$ are installed at the end of Bus 1, Bus 2 and Bus 3 respectively as can be seen from Fig. 1. The operating characteristics of the relays is IDMT and operating time can be calculated by (1), where TMS is time multiple setting and PSM is plug setting multiplier (ratio of secondary current of the line and PS- Plug Setting). The characteristic curves of all three IDMT overcurrent relays are shown in Fig. 3. From, the characteristic graph of Fig. 3 it can be seen that for a fault after bus 3 (fault current is around 1.9 $\mathrm{kA}$ ), relay, $\mathrm{R}_{3}$ works as a primary protection relay (around $0.07 \mathrm{~s}$ ) while relay, $\mathrm{R}_{2}$ works as a back-up protection (around $0.37 \mathrm{~s}$, if necessary) and maintain a coordination interval of 0.3 s. Similarly, for a fault between bus 2 and bus 3 , fault current is around $3.3 \mathrm{kA}$ and $\mathrm{R}_{2}$ is the primary protection operating around $0.32 \mathrm{~s}$ and $\mathrm{R}_{1}$ is the back-up operating around $0.62 \mathrm{~s}$. Assuming grid fault level is $250 \mathrm{MVA}$, the settings of each relay for the network configuration shown in Fig. 1 are calculated and is shown in TABLE II.

$$
O T=\frac{0.14}{P S M^{0.02}-1} \times T M S
$$

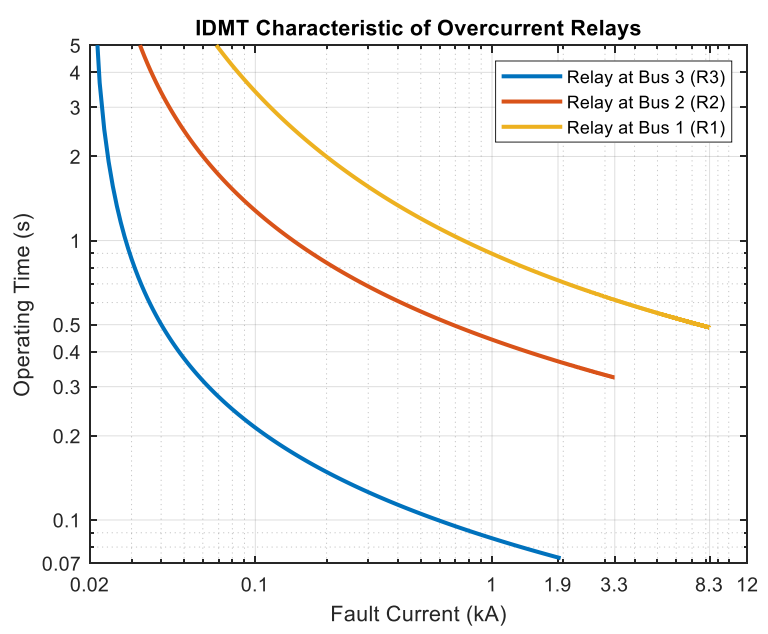

Fig. 3. IDMT characteristics of the overcurrent relays used for the simulation.

TABLE II. SETtINGS OF THE RELAYS USED FOR THE SIMULATIONS

\begin{tabular}{cccc}
\hline Relays & CT Ratio & PS & TMS \\
\hline R1 & 20 & $400 \%$ & 0.34 \\
R2 & 10 & $350 \%$ & 0.22 \\
R3 & 10 & $200 \%$ & 0.05 \\
\hline
\end{tabular}

\section{Performance ANAlysis of OVERCURRENT Relay}

Some of the simulation cases imitating future network scenarios are explained in this section. Furthermore, details explanation of the protection challenges is also provided.

\section{A. Scenario \#1: Variation of Grid Fault Level}

Due to decommission of the large synchronous generation, e.g. nuclear power plants, the grid fault level are expected to decrease. Therefore, in this case scenario, the fault current level in MVA from the grid is decreased form 250 MVA so that weak power system's effect on microgrid protection (i.e. operation time of the overcurrent relays in the network) can be observed. TABLE III presents the operating time (OT) of the relays after fault at different location of the network with decreasing grid fault level (from 250 MVA). Significant change of operating time of the relays can be observed while grid fault level is less than $50 \mathrm{MVA}$.

TABLE III. OPERATING TIME (OT) OF THE RELAYS DURING DIFFERENT FAULTS WITH VARIATION OF GRID FAULT LEVEL

\begin{tabular}{|c|c|c|c|c|c|}
\hline \multirow{2}{*}{$\begin{array}{c}\text { Grid } \\
\text { Fault } \\
\text { Level } \\
\text { (MVA) }\end{array}$} & \multicolumn{2}{|c|}{$\begin{array}{c}\text { Fault After Bus } 3 \\
\left(F_{3}\right)\end{array}$} & \multicolumn{2}{|c|}{$\begin{array}{c}\text { Fault Between Bus } \\
2 \text { and Bus } 3\left(F_{2}\right)\end{array}$} & \multirow{2}{*}{$\begin{array}{c}\begin{array}{c}\text { Fault } \\
\text { Before Bus } \\
2\left(\mathrm{~F}_{1}\right)\end{array} \\
\text { OT of RI }(\mathrm{s})\end{array}$} \\
\hline & $\begin{array}{l}\text { OT of } \\
R 3(s)\end{array}$ & $\begin{array}{c}\text { OT of R2 } \\
(s)\end{array}$ & $\begin{array}{l}\text { OT of } \\
R 2(s)\end{array}$ & $\begin{array}{c}\text { OT of R1 } \\
(s)\end{array}$ & \\
\hline 250 & 0.07 & 0.37 & 0.32 & 0.62 & 0.49 \\
\hline 225 & 0.07 & 0.37 & 0.33 & 0.62 & 0.50 \\
\hline 200 & 0.07 & 0.37 & 0.33 & 0.62 & 0.51 \\
\hline 150 & 0.07 & 0.38 & 0.33 & 0.64 & 0.53 \\
\hline 100 & 0.08 & 0.38 & 0.35 & 0.67 & 0.57 \\
\hline 50 & 0.08 & 0.41 & 0.38 & 0.75 & 0.68 \\
\hline 25 & 0.09 & 0.46 & 0.44 & 0.90 & 0.85 \\
\hline 20 & 0.09 & 0.49 & 0.46 & 0.97 & 0.92 \\
\hline 10 & 0.11 & 0.59 & 0.58 & 1.31 & 1.26 \\
\hline 5 & 0.14 & 0.79 & 0.77 & 2.08 & 2.01 \\
\hline 2 & 0.21 & 1.45 & 1.43 & 9.83 & 9.21 \\
\hline
\end{tabular}


Furthermore, for $20 \mathrm{MVA}$ grid fault level, $\mathrm{R}_{2}$ operates around $0.46 \mathrm{~s}$ for fault, $\mathrm{F}_{2}$ (Fault between Bus 2 and Bus 3), which is significantly high operating time. Generally, undervoltage protection (if voltage is less than $50 \%$ of the nominal value) of the generators are activated around $0.5 \mathrm{~s}$. Therefore, it is expected that the line protection of the network must operate before $0.5 \mathrm{~s}$. However, from the simulation results, it has been observed that there is a possibility of slow operation for $\mathrm{R}_{2}$ for fault, $\mathrm{F}_{2}$ while grid fault level is $20 \mathrm{MVA}$ or power system is weak.

Similar results are also observed for relay, $R_{1}$ for fault $F_{1}$ (fault between Bus 1 and Bus 2). From the TABLE III, it can be seen that OT of $R_{1}$ is relatively high because of the high TMS (the value is set in this way to maintain coordination between the relays). To solve this issue instantaneous property is used with IDMT. The IDMT characteristic with instantaneous property for relay, $\mathrm{R}_{1}$ for fault, $\mathrm{F}_{1}$ is shown in Fig. 4. However, during $20 \mathrm{MVA}$, maximum fault current for fault, $F_{1}$ is around $1 \mathrm{kA}$ and from Fig. 4 it can be seen that OT for $R_{1}$ is still higher than $0.5 \mathrm{~s}$.

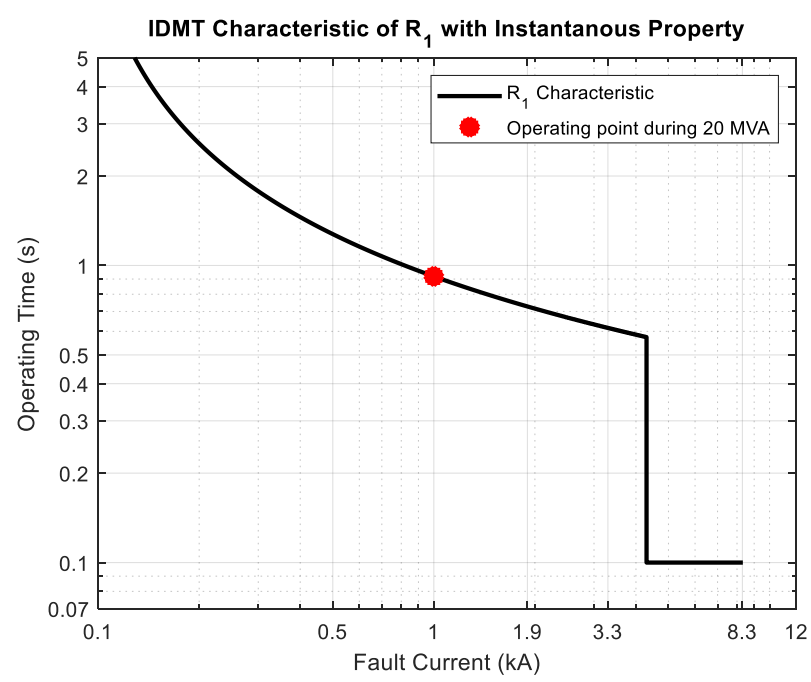

Fig. 4. IDMT characteristic of $\mathrm{R}_{1}$ with instantaneous property.

Thus, based on the simulation results for this case study, it can be concluded that the overcurrent protection for microgrid will operate slowly for the weak grid system (even might not operate while grid fault level is less than 1 MVA), where, grid fault level is less than $25 \mathrm{MVA}$ (which can be an expected fault level due to decommission of large power plants).

\section{B. Scenario \#2: Miscorrdination of the Relays}

Location of faults and IIDGs are varied to observe if they can cause any protection challenges. Two of the examples are explained with simulation results in this section. The first example is presented in Fig. 5, where one IIDG is connected at Bus 3 and fault is at between Bus 1 and Bus $2\left(\mathrm{~F}_{2}\right)$. In this case, relay at Bus $1, R_{1}$ should operate and to disconnect the fault current supply from IIDG, the relay at Bus $2, \mathrm{R}_{2}$ should operate.

However, according to the settings shown in TABLE II, the operating times of the relays, $R_{1}, R_{2}$ and $R_{3}$ are respectively $0.49 \mathrm{~s}, 1.45 \mathrm{~s}$ and $0.21 \mathrm{~s}$ while the fault current contribution from IIDG has not been limited. As mentioned earlier, for fault $F_{1}$, relay $R_{1}$ and $R_{2}$ should isolate the faulted section but from simulation it has been observed that $R_{3}$ is operating faster than $\mathrm{R}_{2}$ which is sympathetic tripping of relay $R_{3}$. Relay $R_{2}$ does not operate and relay $R_{3}$ operates around $1.39 \mathrm{~s}$ (which is very slow) while fault current of the IIDG unit is limited to the $30 \mathrm{~A}$.

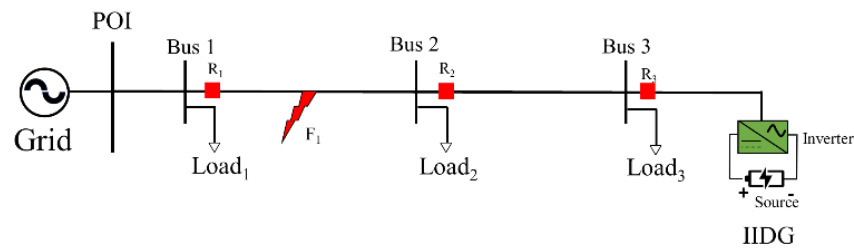

Fig. 5. Example of miscoordiantion of the relays.

Therefore, from this simulation it can be concluded that due to addition of IIDG, there is a possibility of the relays maloperation. The remedy of this case situation could be use of directional overcurrent relays where the relays will detect the flow of current and settings of the relays will be different for different direction of current. Again, the directional overcurrent relays could be expensive than non-directional overcurrent relays.

The second example is shown in Fig. 6, where IIDG is connected to Bus 1 and fault is between Bus 2 and Bus $3\left(F_{2}\right)$. In this case, relay, $\mathrm{R}_{2}$ should clear the fault and $\mathrm{R}_{1}$ should operate as back-up. However, from the simulation it has been observed that the relay, $\mathrm{R}_{1}$ operates faster (with instantaneous property operates around $0.1 \mathrm{~s}$ ) than relay $R_{2}$, which is operating around $0.31 \mathrm{~s}$. The operating points of the relay $R_{1}$ with and without IIDG is shown in Fig. 7. The green point indicates the operating point while IIDG is not connected and work as back-up protection for relay $R_{2}$. The red point indicates the operation for $\mathrm{R}_{1}$ while IIDG is connected, which is in the instantaneous part. As a result, $R_{1}$ is operating faster than $R_{2}$ for fault $F_{2}$, which is the miscoordination between the relays $R_{1}$ and $R_{2}$.

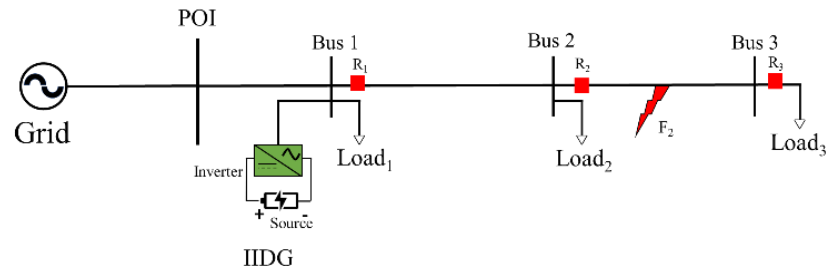

Fig. 6 Miscoordination of relay $R_{1}$ due to fault $F_{2}$ with instantaneous property.

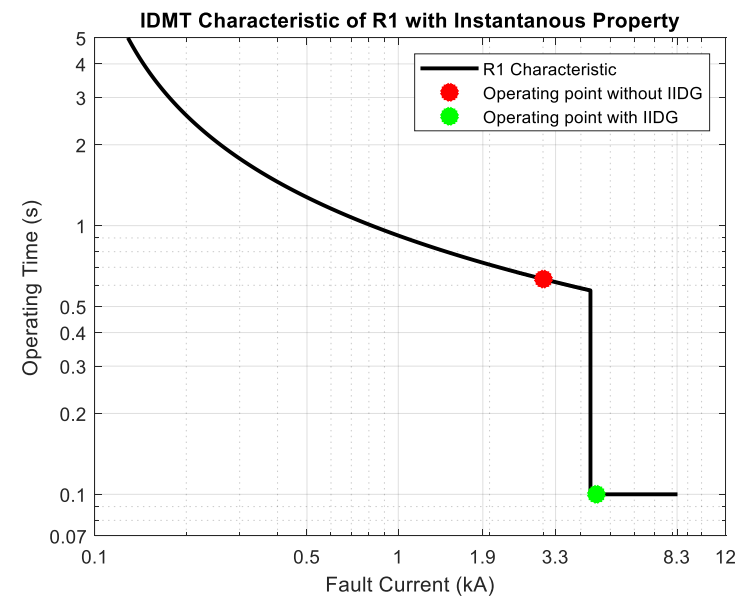

Fig. 7. Characteristics of relay $\mathrm{R}_{1}$ With and Without IIDG. 
However, this simulated case challenge largely depends on the capacity of the connected IIDG or synchronous based DG. This challenge might no take place in case of smallscaled DG and definitely will not be a problem with IIDGs with limited fault current.

\section{Scenario \#3: Islanded Network}

One of the biggest advantages of the microgrid is its autonomous operation while grid is disconnected. Islanding of the network can be two types; (1) intentional islanding and (2) unintentional islanding. Unintentional islanding take place when grid is disconnected from the network but DGs connected to that network does not recognise the grid disconnection and continue to supply power to local loads. This situation can be very dangerous for the following reasons [11].

- Transient over-voltage surge might be created in the islanded network.

- During maintenance, there is risk of life for the maintenance crews.

- Electromechanical torques generated by DGs during islanded mode might cause damage to the connected electrical loads, which eventually might cause health hazards for the consumers.

Intentional islanding in the microgrids is achieved by considering following conditions:

\section{1) By maintaining standard limit of voltage and} frequency.

2) By maintaining stability of the islanded network.

3) By ensuring proper protection of the islanded network.

In this simulation case grid has been disconnected and to maintain stability, and voltage and frequency standard, a grid forming controller is used in the IIDG1 as shown in Fig. 1 and rest of the IIDGs are PQ controlled. The setup for this simulation is same as Fig. 1 except in this case grid is not connected and faults are used in three locations of the network, between Bus 1 and Bus $2\left(\mathrm{~F}_{1}\right)$, between Bus 2 and Bus $3\left(\mathrm{~F}_{2}\right)$ and after Bus $3\left(\mathrm{~F}_{3}\right)$. The operating time of the relays for each fault is represented in the TABLE IV.

TABLE IV. OPERATING TIME OF THE RELAYS DURING ISLANDED MOdE AND COMPARISON WITH GRID CONNECTED TIME

\begin{tabular}{|c|c|c|c|c|}
\hline \multirow{2}{*}{$\begin{array}{c}\text { Fault } \\
\text { Location }\end{array}$} & \multicolumn{2}{|c|}{$\begin{array}{l}\text { Operating time during } \\
\text { islanded mode }\end{array}$} & \multicolumn{2}{|c|}{$\begin{array}{l}\text { Operating time during grid } \\
\text { connected mode ( } 250 \text { MVA) }\end{array}$} \\
\hline & $\begin{array}{c}\text { Primary } \\
\text { Protection } \\
(s)\end{array}$ & $\begin{array}{c}\text { Back-up } \\
\text { Protection } \\
(s)\end{array}$ & $\begin{array}{c}\text { Primary } \\
\text { Protection }(s)\end{array}$ & $\begin{array}{c}\text { Back-up } \\
\text { Protection (s) }\end{array}$ \\
\hline$\overline{F_{3}}$ & 0.25 & 3.54 & 0.07 & 0.37 \\
\hline $\mathrm{F}_{2}$ & 3.45 & $\begin{array}{l}\text { Fault not } \\
\text { detected }\end{array}$ & 0.32 & 0.62 \\
\hline $\mathrm{F}_{1}$ & $\begin{array}{l}\text { Fault not } \\
\text { detected }\end{array}$ & $\mathrm{n} / \mathrm{a}$ & 0.49 & $\mathrm{n} / \mathrm{a}$ \\
\hline
\end{tabular}

As can be seen from TABLE IV, significant change in the operating time of the overcurrent relays can be observed. In the worst-case situation, relay $R_{1}$ does not detect the fault. Furthermore, detection of fault is now depended on the number and capacity of the IIDGs.

\section{Scenario \#4: Bidirectional Power Flow}

A case scenario is demonstrated in this section where microgrid might not be protected due to bidirectional power flow. This scenario can be explained with the aid of Fig. 8 .

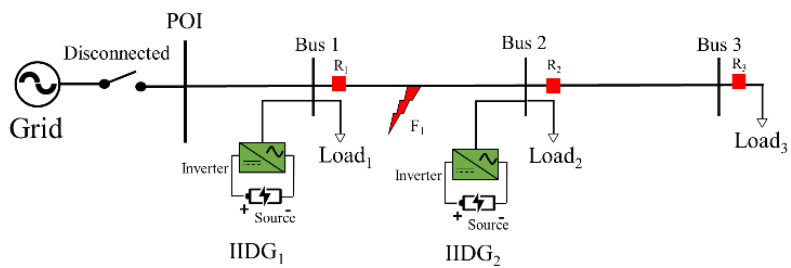

Fig. 8. Microgrid protection challenge due to bidirectional power flow.

In this case, due to fault, $\mathrm{F}_{1}$, both IIDG will contribute fault current towards the fault. Now, relay, $\mathrm{R}_{1}$ might detect the fault depending on the fault current contribution from IIDG1 and settings of the relay (although there is less possibility as described earlier). However, there is no relay in the network which can isolate the $\mathrm{IIDG}_{2}$ fault current contribution towards the faulted section unless the IIDG's protection is activated. Again, disconnection of $\mathrm{IIDG}_{2}$ can cause isolation of all the consumers and loads.

\section{CONCLUSIONS AND FUTURE WORK}

Different simulation cases are demonstrated in this paper to illustrate the protection challenges in the microgrid and to analyse the performance of the overcurrent relays with large integration of renewable based generation. It can be concluded that overcurrent relay is no longer suitable for the protection of microgrid and it is essential to design and propose a protection scheme which does not depend on the magnitude of current to detect and coordinate the protection system.

\section{REFERENCES}

[1] J. M. Guerrero et al., "Distributed Generation Toward a New Energy Paradigm," Ieee Industrial Electronics Magazine, vol. 4, no. 1, pp. 5264, Mar 2010

[2] R. H. Lasseter, "MicroGrids," 2002 Ieee Power Engineering Society Winter Meeting, Vols 1 and 2, Conference Proceedings, pp. 305-308, 2002.

[3] F. Farzan, S. Lahiri, M. Kleinberg, K. Gharieh, F. Farzan, and M. Jafari, "Microgrids for Fun and Profit," Ieee Power \& Energy Magazine, vol. 11, no. 4, pp. 52-58, Jul-Aug 2013.

[4] N. Hatziargyriou, H. Asano, R. Iravani, and C. Marnay, "Microgrids," Ieee Power \& Energy Magazine, vol. 5, no. 4, pp. 78-94, Jul-Aug 2007.

[5] D. E. Olivares et al., "Trends in Microgrid Control," Ieee Transactions on Smart Grid, vol. 5, no. 4, pp. 1905-1919, Jul 2014

[6] A. Hooshyar and R. Iravani, "Microgrid Protection," Proceedings of the Ieee, vol. 105, no. 7, pp. 1332-1353, Jul 2017.

[7] "IEEE Application Guide for IEEE Std 1547(TM), IEEE Standard for Interconnecting Distributed Resources with Electric Power Systems," IEEE Std 1547.2-2008, pp. 1-217, 2009.

[8] M. A. U. Khan, Q. Hong, A. Dyśko, C. Booth, B. Wang, and X. Dong, "Evaluation of fault characteristics in microgrids dominated by inverter-based distributed generators with different control strategies."

[9] M. A. U. Khan, Q. Hong, A. Dyśko, and C. Booth, "Review and Evaluation of Protection Issues and Solutions for Future Distribution Networks," in 2019 54th International Universities Power Engineering Conference (UPEC), 2019, pp. 1-6.

[10] M. A. U. Khan and C. D. Booth, "Detailed analysis of the future distribution network protection issues," The Journal of Engineering, vol. 2018, no. 15, pp. 1150-1154, 2018.

[11] Z. K. Shuai, C. Shen, X. Yin, X. Liu, and Z. J. Shen, "Fault Analysis of Inverter-Interfaced Distributed Generators With Different Control Schemes," Ieee Transactions on Power Delivery, vol. 33, no. 3, pp. 1223-1235, Jun 2018

[12] M. A. U. Khan, Q. Hong, A. Dysko, and C. Booth, "An Active Protection Scheme for Islanded Microgrids," presented at the The 15th International Conference on Developments in Power System Protection (DPSP), Liverpool, United Kingdom, March 2020.

[13] T. Haggis, "Network Design Manual," EON Central NetworksDecember 2006 December 2006. 
